\title{
Cultura: uma visão
}

\section{antropológica ${ }^{* * *}$}

Sidney W. Mint: ***

Traduzido por James Emanuel de Albuquerque ${ }^{* * * *}$

Define-se cultura como uma propriedade humana ímpar, baseada em uma forma simbólica, 'relacionada ao tempo', de comunicação, vida social, e a qualidade cumulativa de interação humana, permitindo que as ideias, a tecnologia e a cultura material se "empilhem" no interior dos grupos humanos.

Palavras-chave: Cultura-Sociedade - História-Superindividual - Superorgânico - Compadrazgo

\section{Culture: an Anthropological View}

Culture is defined as a uniquely human property, one based on a symbolic, "timebinding' form of communication, social life, and the cumulative quality of human interaction, enabling ideas, technology, and material culture to "pile up" within human groups.

Keywords: Culture - Society - History - Superindividual - Superorganic - Compadrazgo

\footnotetext{
* Tradução recebida e aprovada para publicação em julho de 2009.

** Tradução do ensaio "Culture: An Anthropological View publicado originalmente em The Yale Review, XVII (4), 1982, p. 499-512. Revisão de Leda Maia, Maria Regina Celestino de Almeida e Cecília Azevedo.

${ }^{* * *}$ Research Professor, Department of History, Johns Hopkins University.

**** Mestrando no PPGHIS - IFCS da Universidade Federal do Rio de Janeiro em março de 2005.
} 


\section{Culture : un regard anthropologique}

La culture est définie comme une propriété humaine unique, basée sur une forme symbolique reliée au temps, de communication, de vie sociale, et sur la qualité cumulative de l'interaction humaine, ce qui permet ainsi que la culture matérielle et la technologie s'accumulent dans les groupements humains.

Mots-clés : Culture - Société - Histoire - Superindividuel - Superorganique Compadrazgo

Desde 1877, quando Edward Burnett Tylor empregou pela primeira vez o termo "cultura" para referir-se a todos os produtos comportamentais, espirituais e materiais da vida social humana, os sentidos mais antigos e restritos desse termo foram perdendo terreno.

Entre esses sentidos mais antigos de cultura, dois, em especial, sobreviveram em formato modificado. Um deles é que em certas sociedades algumas pessoas possuem cultura, e outras não. O outro se refere ao conceito, próximo embora bastante diferente, de que certas sociedades possuem cultura, enquanto outras não. Estas duas idéias diferem qualitativamente; a primeira estabelece diferenças de grau, e a segunda, diferenças de espécie.

No primeiro caso - a sociedade na qual as pessoas que possuem cultura distinguem-se das que não a têm - a linha divisória é estabelecida usualmente entre discurso apropriado e inapropriado, comportamento apropriado e inapropriado, e contrastes similares. Cultura, nessa visão, seria um conjunto formado por nascimento, posição social, educação e criação, que se traduziria em idéias e comportamentos; seria portanto também uma questão de privilégios. No segundo caso - sociedades com cultura, e sociedades sem cultura - a cultura em si era vista como o produto de certas peculiaridades da história do grupo. Sua gênese poderia ser atribuída ao gênio de seus portadores, a alguns heróis míticos, a uma divindade benigna, ou o que seja - mas apenas algumas sociedades teriam a sorte de possuí-la. E, nestes dois significados antigos, a diferença estava em estabelecer se essa cultura poderia ser transmitida tanto para aquelas sociedades cujos membros não a possuíam, quanto para aquelas onde apenas alguns de seus membros a possuíam.

Franz Boas com certeza fez mais do que qualquer outro antropólogo pela promoção de um conceito de cultura que englobasse a espécie humana - segundo o qual todos os grupos humanos, e não outras formas de vida, manifestam esta propriedade ou capacidade. O interesse de Boas se situava 
particularmente nas sociedades comumente rotuladas de "primitivas". Suas características comuns mais notáveis provavelmente seriam o tamanho reduzido, o desconhecimento da escrita, tecnologia sem máquinas, e uma ordem social largamente construída em torno de laços familiares. No tempo de Boas, tais sociedades estavam sendo "descobertas" - e destruídas - numa proporção acelerada; quando começou a lecionar em Columbia, nos primórdios do século $\mathrm{XX}$, Boas ainda pôde testemunhar os processos de descoberta e destruição na região noroeste do Pacífico, onde realizou seu próprio trabalho de campo, bem como no resto da América "Nativa". Foi também o período, sem dúvida, em que os avanços tecnológicos eram apresentados como a mais convincente medida da superioridade da civilização - o fim do verdadeiro "progresso" pelos líderes do Ocidente.

Por esta razão, acredito, a ênfase teórica de Boas voltou-se não apenas para a exclusividade humana das propriedades da cultura, distribuída igualmente por todos os grupos sociais independentemente de seus níveis de desenvolvimento tecnológico, mas também para as propriedades particulares de cada uma das culturas. Ele foi visto como um "antievolucionista", e creio que esta visão é correta, pelo menos na medida em que ele se afastou do "Darwinismo" social do seu tempo - uma perspectiva que pode ser exemplificada de forma concisa, em minha opinião, na conclusão do destacado sociólogo de Yale, William Graham Summer, segundo a qual "os milionários são um produto da seleção natural, que atua no conjunto dos homens para escolher aqueles que satisfazem as exigências para certo trabalho a ser feito".

A preocupação de Boas com os conhecimentos grupais particulares de outros povos - principalmente dos menos numerosos, desconhecedores da escrita e limitados tecnicamente - parece ter contribuído, entre outras coisas, para que os cidadãos das grandes sociedades, poderosas, tecnicamente desenvolvidas e agressivas da América e Europa desenvolvessem uma visão mais objetiva de si próprios.

Talvez nenhum dos escritos de Boas tenha revelado de maneira mais marcante o seu ponto de vista como a carta que escreveu a um parente durante a sua primeira visita aos esquimós, ao iniciar a sua carreira de antropólogo. Era dezembro de 1883. Boas, seu criado Wilhelm e o esquimó que os acompanhava, de nome "Sigma", tinham viajado sob condições altamente adversas para o extremo noroeste do Estreito de Cumberland. Caminhando por 36 horas, na maior parte desse tempo perdidos, vagando pelo gelo a $45^{\circ} \mathrm{C}$ negativos, 
suas provações só tiveram fim quando foram convidados a entrar em um iglu esquimó, onde puderam se aquecer, comer e dormir. "Não é realmente um belo costume", observou Boas, "que estes 'selvagens' sofram todo tipo de privações em comum, mas nos momentos de alegria, quando alguém traz um butim da caçada, eles se juntem para comer e beber? Eu muitas vezes me pergunto quais as vantagens que a nossa 'boa sociedade' possui sobre a desses 'selvagens'. Quanto mais observo seus costumes, mais me convenço de que não temos por que nos considerarmos superiores. Onde, em nossa sociedade, encontraríamos tamanha hospitalidade? Aqui, sem a menor queixa, eles estão dispostos a fazer todos os trabalhos que lhes são exigidos. Nós não temos o direito de criticá-los por sua forma de vida e suas superstições, que podem nos parecer ridículas. Nós, pessoas 'altamente educadas', somos piores, relativamente falando. $\mathrm{O}$ medo das tradições e velhos costumes está profundamente arraigado na humanidade, e do mesmo modo que regula a vida aqui, impede $o$ progresso para nós. Acredito que todos os indivíduos e todos os povos se vêem diante do conflito de abandonar a tradição e seguir o caminho da verdade. Os esquimós estão sentados ao meu redor, as bocas cheias de fígado de foca cru (a gota de sangue no verso do papel mostra que eu também participei). Como ser pensante, o resultado mais importante desta viagem para mim está no fortalecimento do meu ponto de vista de que o conceito de um indivíduo 'cultivado' é meramente relativo, e que o valor de uma pessoa deve ser julgado pelo seu Herzenbildung. ${ }^{1}$ Esta qualidade está presente ou ausente aqui entre os esquimós, tanto quanto entre nós."

Boas viu a cultura como um traço distintivo da humanidade; ele resistiu aos vários exercícios classificatórios que procuraram estabelecer hierarquias entre as culturas; ele lembrava aos antropólogos que sua tarefa primordial era registrar cuidadosamente as informações etnográficas específicas sobre o maior número possível de sociedades "primitivas" diferentes, antes de seu desaparecimento - eis os aspectos básicos de sua posição. No entanto, parece não ter tido muito interesse no desenvolvimento de uma "teoria da cultura", da cultura na forma abstrata - algo que viria a se tornar o hobby de muitos antropólogos.

Hoje, cerca de quarenta anos após a morte de Boas, confesso que deveria estar mais preocupado em admitir que não estamos mais próximos (na verdade, alguns poderiam dizer que estamos mais afastados) de qualquer consenso

${ }^{1}$ Nota do Tradutor: em alemão no original. 
sobre a natureza da cultura. É mais do que "curioso" o fato de quase todos os meus colegas [antropólogos] concordarem que "cultura" é o conceito mais fundamental do nosso campo de saber - mesmo admitindo que não é possível defini-la. Cultura seriam ideias? Seriam padrões? Seriam atos? Seriam as consequências, incluindo os objetos materiais, desses atos? Seria tudo isso, uma relação entre alguns, ou todos eles, ou uma coisa inteiramente diversa? Por incrível que pareça, nós não temos a menor ideia ou, melhor dizendo, temos centenas delas. Isso talvez se deva a um desejo por parte de quase todos os antropólogos de dizer alguma coisa totalmente original sobre cultura. Não sei bem com o que comparar esta aspiração tão amplamente partilhada, mas entre os mais considerados mestres da minha área, ao menos nos EUA, quase todos escreveram alguma coisa sobre essa questão, embora nenhum deles tenha chegado a um consenso.

Transformando em virtude o que parece no momento uma necessidade, alguns de meus colegas argumentam que é a despreocupação dos antropólogos, agindo como se soubessem o que é cultura, que lhes possibilita propor questões investigativas sobre o comportamento humano. Talvez seja assim. A verdade é que a nossa incerteza, ou tantas certezas, nos ajudaram a bloquear a fronteira que separa as áreas humanas das ciências, desempenhando o papel de guarda de portão de que alguns de nós tanto se vangloriam. Embora não esteja certo de que essa perspectiva possa ser vista com otimismo, julgo salutar termos pelo menos uma doutrina, cujos defensores em sua maioria estejam preparados para concordar que os seres humanos não são nem sofisticados computadores, nem macacos extremamente engenhosos, nem feitos à imagem e semelhança de um deus cristão. E, mais ainda, me compraz a idéia de que muitos de nós, se não a maioria, nem mesmo consideram que os prós e os contras destas postulações são questões merecedoras de interesse.

Admitindo-se que não existe unanimidade no círculo da antropologia quanto à definição do seu conceito mais básico, o que mais deve ser dito? Primeiramente, é possível tomar partido na questão das concepções "histórica" versus "não-histórica" (ou a-histórica) de cultura. Enquanto vários acadêmicos têm criticado a visão de cultura de Alfred Kroeber, denominada "superorgânica" (bem como o termo em si, originário de Spencer), o que Kroeber tinha em mente é claro e, acredito eu, convincente: "simplesmente, quando falamos em cultura, estamos trabalhando com algo que é orgânico [ou seja, produzido por organismo humano] mas que pode ser visto como algo mais que orgânico se for para ser plenamente inteligível para nós". 
Kroeber argumenta, adicionalmente, que a cultura é "superindividual" bem como "superorgânica":

existem certas propriedades da cultura - tais como transmissibilidade, alta variabilidade, padrões de valor, influência em indivíduos - que são difíceis de explicar, ou cuja significância é mais difícil de encontrar, estritamente em termos de composição orgânica ou personalidades de indivíduos. Essas propriedades ou qualidades da cultura evidentemente se fixam não no indivíduo orgânico homem enquanto tal, mas nas ações e nos produtos de comportamento de sociedades de homens - ou seja, na cultura.

Esse trecho pode parecer enigmático, mas para mim significa que o comportamento humano não pode ser plenamente entendido pelo (ou reduzido ao) exame de indivíduos isoladamente. Tudo o que eles são, bem como o que eles pensam e fazem, seus atos e as consequências de seus atos, é sempre social. E por ser este o caso, o comportamento social não pode ser reduzido a uma análise do comportamento individual.

Confesso que nunca entendi plenamente por que essas asserções despertaram não apenas ceticismo, mas até certa animosidade. Kroeber, por insistir em propriedades da cultura "extrassomáticas", transmitidas socialmente, portanto coletivas e cumulativas, foi acusado de postular alguma forma de influência externa impalpável, mas poderosa, à qual os humanos estariam sujeitos inconsciente e inapelavelmente. Entretanto, parece claro para mim que Kroeber estava na verdade dizendo algo mais simples. Se os seres humanos são por natureza sociais e também extremamente dependentes na infância e na menoridade; se uma grande massa de aprendizado social é necessária para torná-lo "cultivado" em sua própria sociedade (para o qual Melville Herskovits criou o termo agora amplamente empregado "enculturação"); se, resumindo, ser humano significa a necessidade de absorver um volume suficiente de formas culturais da sua própria sociedade, para ser considerado humano em termos específicos da cultura; então eu acredito que as asserções de Kroeber são tanto "não excepcionais" quanto "não excepcionáveis". A analogia mais fácil e mais convincente é provavelmente a linguagem, e Kroeber a utiliza:

Novamente, a língua inglesa é uma parte da cultura. A faculdade de falar e entender alguma ou qualquer linguagem é orgânica: é uma faculdade da espécie humana. Os sons das palavras são, é claro, produzidos pelos indivíduos, não pela espécie. Mas a agregação total das palavras, formas, gramática e significados que constituem a língua inglesa são o produto cumulativo e conjunto 
produzido por milhões de indivíduos ao longo de muitos séculos. Nenhum de nós criou ou inventou o inglês que fala. Nós o falamos como ele chegou até nós, pronto, vindo de seus milhões de indivíduos predecessores pelos muitos séculos passados. O inglês é obviamente 'superindividual' no sentido de que é infinitamente maior e mais significante do que o discurso de qualquer homem individualmente, e por influenciar sua fala infinitamente mais do que ele possa esperar que sua fala influencie a língua inglesa. $\mathrm{E}$ a língua inglesa é 'superorgânica' em razão do fato de que suas palavras e significados não são consequências diretas do fato de serem organismos humanos - senão todos os homens falariam de forma tão similar quanto andam de forma similar. Em vez disso, o modo como falam depende preponderantemente de como a sociedade em que eles cresceram falava antes.

Com este exemplo, Kroeber afirma que "um fato cultural é sempre um fato histórico; e o entendimento mais imediato e, usualmente, mais completo desse fato que poderemos obter é um conhecimento histórico". Esta asserção até certo ponto moderada, que aparece de uma forma ou de outra em seu trabalho ao longo dos anos e nos trabalhos de muitos outros alunos de Boas, longe esteve, no entanto, de ser considerada auto- explicativa, nos anos 1940, quando a antropologia social britânica estava em ascensão. Nessa época, seus líderes afirmavam que a história era irrelevante para nosso entendimento de sociedades que desconheciam a escrita, ou então meramente um último recurso para antropólogos sem imaginação.

Alexander Lesser, quando se viu envolvido em uma controvérsia, ainda no início de sua carreira, com um dos maiores antropólogos "funcionalistas" britânicos, A. R. Radcliffe-Brown, escreveu em 1934:

Nós observamos tais e tais eventos acontecendo. Entretanto, muitas coisas estão sempre acontecendo simultaneamente. Como podemos determinar se estas coisas acontecidas ao mesmo tempo estão ou não relacionadas entre si? Por certo, podem ser eventos contemporâneos ou mesmo seriais, não porque estivessem relacionados entre si, mas em função de seus condicionantes, não determinados nem observados, terem causado a sua ocorrência em tempos subsequentes. Em resumo, eventos contemporâneos ou associados podem ser meramente 'coexistências'. Cultura, em qualquer tempo, é antes de tudo uma massa de eventos 'coexistentes'. Se estamos tentando definir relações entre tais eventos, é impossível, na visão da conhecida historicidade das coisas, presumir que as relações estejam na superfície contemporânea dos eventos. Qualquer acontecimento é determinado mais pelos eventos ocorridos antes da ocasião em questão do que pelo que podemos observar contemporaneamente com ele. Assim que nos voltamos para os eventos anteriores para termos a compreensão 
de eventos observados, estamos nos voltando para a história. A história nada mais é do que isso. É a utilização do fato condicionante da historicidade para a elucidação de eventos observados. [Grifo adicionado.]

Para o que propomos aqui, pouca importância têm os motivos de americanos e britânicos terem divergido tão radicalmente sobre a utilidade de materiais históricos na análise da cultura, particularmente desde que a controvérsia parece atualmente ter-se resolvido em favor de uma combinação de abordagem "histórica" e "funcional" - pelo menos para aqueles que dão importância a essas coisas. Mas a aceitação da história (ou de "explanações históricas") na antropologia levanta questões sobre a natureza da "explanação" em si. Convencionava-se assumir na antropologia que "cultura" (significando o modo de vida particular de um grupo definido) e "sociedade" (significando um grupo organizado tendo continuidade ao longo do tempo) são meios convenientes de se falar de duas faces de um mesmo fenômeno que se encaixam. Temos "um povo", organizado como uma "sociedade", que possui um conjunto de instituições, tecnologias, linguagens, crenças, valores - em resumo, uma "cultura". Cultura era, portanto, associada de algum modo a um grupo organizado.

Uma versão desta engenhosa, mas até certo ponto enganosa harmonia aparece no equipamento teórico de quase todo antropólogo social/cultural, levantando questões históricas genuínas. Há muito tempo, Eric Wolf argumentou que "erramos ao pensar em uma cultura em cada sociedade, uma subcultura em cada segmento social, e esse erro prejudicou nossa capacidade de ver as coisas dinamicamente". Wolf prossegue, sugerindo que "é possível que um grupo humano possa ter mais do que uma cultura, diversificar sua abordagem em relação à vida, ampliando seu campo de manobras através de um processo de generalização, assim como é possível que um grupo humano se especialize, restringindo-se a um conjunto de formas culturais e evitando quaisquer alternativas possíveis".

Mas, uma vez que a possibilidade de certa falta de identidade entre "uma cultura" e "uma sociedade" tenha sido considerada, ambos os termos se tornaram de alguma forma mais problemáticos. Na formulação de Wolf - que considero a mais instigante entre muitas outras na antropologia - os termos são definidos como se segue:

Por cultura eu entendo as formas desenvolvidas historicamente através das quais os membros de uma determinada sociedade se relacionam entre si. Por 
sociedade eu entendo o elemento de ação, de manobras humanas dentro de um campo constituído pelas formas culturais, de manobras humanas que almejam tanto a preservação de certo equilíbrio de oportunidades e riscos na vida quanto a sua mudança. A maioria dos antropólogos 'culturais' considera as formas culturais tão limitadoras, que terminam por negligenciar inteiramente $o$ elemento de manobras humanas que flui através dessas formas e em torno delas, pressionando-os contra seus limites ou desempenhando diversos conjuntos de formas contra o meio... A cultura passada certamente estrutura o processo de percepção, mas a manobra humana não é sempre consciente e racional: ao considerarmos os dois aspectos - a visão das formas culturais definindo o campo de manobras humano, e a visão da manobra humana sempre exercendo pressão sobre as limitações inerentes às formas culturais - podemos chegar a uma forma mais dinâmica de apreensão das verdadeiras tensões da vida.

Essa perspectiva, se bem entendi, presume que atores individuais por vezes percebem oportunidades entre as práticas existentes, oportunidades que são consistentes com práticas passadas e ainda assim particularmente adequadas às suas próprias inclinações pessoais. Essas percepções estão de acordo com certos tipos de normas, que as pessoas aprenderam por "enculturação". Mas elas contêm a promessa de um benefício especial, futuro ou imediato; um casamento vantajoso, uma compra oportuna, um favor concedido, uma festa marcada, uma punição diminuída. Para seu exemplo Wolf recolheu dados de seu próprio trabalho de campo. Ainda que eu não pretendesse abordar a etnografia neste ponto, pode ser útil detalhar um pouco mais o exemplo de Wolf, para solidificar o argumento.

No final dos anos 1940, estávamos ambos fazendo trabalhos de campo em Porto Rico - Wolf em uma localidade nas montanhas onde as fazendas variavam em tamanho de centenas de quilômetros quadrados a uns pouco lotes, e os fazendeiros desde os muito ricos até pequenos trabalhadores sem terra; enquanto eu estava em uma comunidade na planície onde praticamente toda a terra pertencia ou estava arrendada a uma única empresa norte-americana de produção de açúcar. Essas localidades obviamente se diferenciavam em muitos aspectos, assim como as situações de vida de seus habitantes. Como Wolf e eu comparávamos frequentemente nossas descobertas, cedo percebemos certas diferenças no sistema do ritual católico do compadrio, ou apadrinhamento batismal (em espanhol, compadrazgo), no modo como era empregado nas comunidades que estávamos estudando.

De uma maneira geral, os associados à pesquisa de Wolf procuravam os mais ricos para serem padrinhos de seus filhos, e por sua vez esta elite apa- 
rentemente aceitava prontamente tais convites. Entretanto, na comunidade que eu estava estudando, a população preferia escolher vizinhos e amigos, ou parentes próximos, para serem seus compadres. O povo de cada lugar tinha boas explicações para suas escolhas. Os integrantes da pesquisa de Wolf, que procuravam a camada mais rica, argumentavam com oportunidades de emprego, medicamentos em tempos de crise, empréstimos emergenciais de dinheiro, sementes ou animais; os mais ricos aceitavam pensando na obtenção de votos, mão-de-obra suplementar, pequenas tarefas, ou serviços domésticos. Os do meu grupo, referindo-se aos seus pares de classe, argumentavam com a distância e a falta de confiança nos padrinhos ricos, que não teriam verdadeiro interesse no afilhado, e poderiam simplesmente "comprar" o parentesco. Mesmo quando lhes foi sugerido que o prefeito, o farmacêutico, ou o médico poderiam ser aparentados úteis, eles rejeitaram o argumento por não merecer qualquer consideração. Com efeito, eles perguntaram com que propósito alguém iria se humilhar, apenas para depois descobrir que o relacionamento não era sincero? Era melhor escolher um companheiro de trabalho; um cunhado; um vizinho, com quem poderiam trocar um prato de comida; um companheiro de partido político. Nem riqueza, nem influência, nem poder, mas a proximidade de algum laço já existente, esse era o fator decisivo.

Essas diferenças resultaram em dois padrões de relacionamento social muito contrastantes, mesmo que ambos os padrões possam ser facilmente relacionados com a mesma forma cultural básica. Mas certamente cada um foi construído sobre condições sociais e econômicas prévias, onde as escolhas foram feitas de acordo com as percepções que cada um tinha de suas próprias oportunidades. Houve, pode-se dizer, uma "busca de sentido" entre situações nas quais os parâmetros extremos de ação já tinham sido predefinidos por eles. Essas fronteiras, ou estruturas externas variáveis para a manobra, são construídas sobre dispositivos de classificação social tais como classe e raça e outros critérios, que usualmente mudam lentamente - e, para grupos inteiros, geralmente apenas através de uma reconstrução revolucionária do sistema social.

O compadrazgo, instituição na qual esta gama de manobras individuais foi percebida, é um produto histórico, e a sua história pode ser traçada por muitos séculos (com efeito, Wolf e eu tentamos isso em um artigo anterior). Enquanto complexo de formas institucionais, o compadrazgo se presta facilmente a um tratamento histórico, e pode ser estudado não apenas em termos 
de sua difusão através do mundo católico e catolicizado (como na América Latina), mas também em termos de sua redução e desgaste em regiões como o norte da Europa e o mundo protestante em geral.

Entretanto, quando alguém passa do estudo do compadrazgo, enquanto conjunto de formas desenvolvidas e derivadas historicamente, para um corpo vivo de oportunidades dentro do qual as pessoas invocam suas capacidades de manobra, esticando uma ou outra regra de modo a maximizar suas próprias vantagens percebidas, está passando do aspecto cultural para o aspecto social do fenômeno. Wolf registrou que os compadres da minha comunidade poderiam obter grandes benefícios com seu compadrio, mas "o coparentesco ritual os vincula de forma particular e, portanto, se mostra pouco adaptável às manobras humanas no caso de [algumas atividades coletivas como] uma greve envolvendo toda a plantação, que requer uma ação através de organismos como um sindicato com características universalizadas". Mas ele também notou que os laços de coparentesco rituais e os sindicatos, embora sejam formas conflituosas e contraditórias em algum contexto, podem ambas sobreviver, a despeito de sua contraditoriedade:

Em um nível de ação, as duas formas e o jogo que elas tornam possível têm uma função complementar; em outro nível de ação, contudo, elas interferem e contradizem uma à outra. Nesta situação, ambas as formas podem sobreviver, $\mathrm{e}$ sobreviver também em seu potencial combinado de tensão e interferência.

Pretendo retornar a essa afirmação conclusiva mais tarde. Mas, tendo anteriormente argumentado que a cultura deve ser vista historicamente para que seja afinal entendida, gostaria de agregar outra condição, derivada da discussão precedente. A formulação "uma cultura, uma sociedade" não apenas limita nossas interpretações; ela também tende a falsear a forma de representação dos modos pelos quais uma cultura, enquanto corpo de materiais historicamente derivados, está encarnada nos eventos sociais.

Alguns tratamentos das distinções cultura/sociedade partem da hipótese de que estes seriam aspectos independentes, apesar de interdependentes, da vida social - um, a cultura, relacionado à significação, e o outro, a sociedade, relacionado aos objetivos dos atores no sistema em curso (uma visão que aparece, por exemplo, nos primeiros trabalhos de Clifford Geertz). Nessa visão, uma perda de entrosamento entre o social e o cultural pode produzir tensão (e mudança) no sistema em si. Mas essa interessante formulação não leva muito em conta as possibilidades de variação tanto dentro da cultura quanto dentro 
da estrutura social - bastante distinta da promessa analítica de sua oposição conceitual. O exemplo que já mencionei dos trabalhos de campo de Wolf, e também do meu, subentende alguma coisa sobre variabilidade dentro de um campo singular de materiais historicamente derivados, no que se refere aos usuários. Ele introduz na discussão o conceito de que vários tipos de diferenças, inclusive as diferenças muito importantes de destino econômico e oportunidades de vida, podem modificar radicalmente quaisquer formas particulares, dentre as alternativas existentes em um sistema cultural que as pessoas possam empregar, bem como o significado que estas formas possam ter para elas. Esta é, acredito, a primeira vez que emprego o termo "significado" aqui; e suspeito que possa ser a última, posto que os argumentos que este termo pode levantar são com certeza abundantes. Mas quando trabalhamos com o que pretendem os atores de um sistema social, atores que empregam uma variante cultural em vez de outra em diversos pontos de suas vidas, parece-nos necessário enfatizar que a relação entre intenção, ato e consequência não é uma relação invariante. Pessoas em posições diferentes podem concebivelmente fazer a mesma coisa, pretendendo coisas bem diferentes ao fazê-la, e provocar consequências bem diferentes através de seus atos similares.

Até aqui, minha argumentação consistiu em afirmar que cultura é um produto histórico, e historicamente mais bem entendido; que "cultura" e "sociedade", embora separáveis conceitualmente e úteis quando utilizadas assim, não são nem perfeitamente coerentes em si mesmas, nem necessariamente congruentes entre si; e que atores em um sistema singular podem empregar formas culturais variáveis, mas igualmente aceitáveis no curso de sua manobra social.

Sobre este assunto, gostaria de acrescentar algumas referências ao relacionamento entre formas culturais e as que ocupam posições muito diferentes dentro de uma mesma sociedade. Durante os anos 1960 houve um breve movimento na antropologia, e na literatura a ela relacionada, no qual "cultura" foi equiparada de diversas formas a classe social - classes sociais diferentes sendo dotadas de diferentes culturas, e assim por diante. Parece-me, atualmente, que nada disso resultou em grandes esclarecimentos; a chamada "cultura da pobreza" foi a variante mais falada de um argumento que parece ter tido um pequeno poder de permanência. Não considero demonstrável o fato de que classes diferentes possuam culturas diferentes em um sentido rigoroso, não mais do que penso ser demonstrável a existência de uma só cultura coerente em cada sociedade. 
Mas o que está claro para mim é que as pessoas conduzem a maior parte das suas ações com base em suas experiências e aprendizados passados. Tais aprendizados e experiências podem ser amplamente compartilhados, mesmo de uma maneira não uniforme. Os hacendados de Wolf e os meus obreros, por exemplo, podem ter compartilhado algum entendimento convencional, como nós antropólogos gostamos de dizer, sobre o apadrinhamento ritual. Mas esses entendimentos são pelo menos tão notáveis pelo que se entende por diferente, quanto pelo que é entendido como igual. Podemos dizer que um hacendado, que utiliza um instrumento para obter mão-de-obra barata ocasional, e um obrero, que utiliza o mesmo instrumento para obter um compromisso de apoio em situações de emergência, estão compartilhando a mesma cultura neste caso, por apelarem a um suposto repertório de idéias comuns. Mas imagino que essas idéias comuns - mesmo assumindo que possamos descobri-las e validar sua existência intersubjetiva - não terão tanta importância seja como uma indicação, seja como uma explicação para o que está acontecendo.

Esses indivíduos agem diferentemente porque seus interesses são diferentes, porque eles estão postados em cantos diferentes do sistema social, porque suas influências entre si não são nem estáticas nem simétricas. Quando tais indivíduos parecem compor grupos, grupos estes que agem diferentemente em terrenos semelhantes, não é porque necessariamente as "culturas" desses grupos são qualitativamente diferentes, mas porque as alternativas culturais, percebidas por eles como mais apropriadas no momento, emergem em contextos sociais específicos. Não se trata simplesmente de uma questão de diferenças de classe em cultura, ou "subcultura" ou "cultura de classe" - "pacotinhos" arrumados de material cultural anexados a "grupinhos" organizados. As classes não podem ser meticulosamente dispostas de uma forma tão simples, cada uma possuindo seus padrões normativos distintivos.

As classes, como a própria cultura, são processos. Elas tomam forma ao longo do tempo, e são forjadas, assim como afirma E. P. Thompson, pela sua própria experiência. Acredito que, inevitavelmente, os antropólogos interessados em cultura no mundo moderno terão de encarar o fato de que a maneira - e a maneira correta - com que as pessoas conduzem suas vidas desempenhará papel imensamente importante na forma como a experiência é objetivada e transformada em idéias de um modo progressivo e contínuo. As pessoas adquirem experiência enquanto estão sendo acionadas e enquanto agem. Na maior parte do tempo e na maioria das formas, elas agem de acordo 
com um código socialmente herdado de comportamento padronizado, um código histórico de longa permanência. Mas esse código não é jamais uma camisa-de-força; existem escolhas e alternativas. Estas - incluindo a opção pela não ação - são utilizadas em várias permutações, embora finalmente sujeitas às condições externas.

Tais condições externas variam de acordo com diferentes grupos, é claro, e estão sujeitas ao controle de diferentes formas. Grupos diferentes podem escolher, em sua maioria, soluções diferentes (e às vezes potencialmente contraditórias ou conflitantes), mesmo quando tais soluções em geral se enquadrem em alguma classe de alternativas culturalmente aceitáveis.

"A classe se forma", escreve Thompson, "enquanto homens e mulheres vivem suas relações produtivas, e enquanto eles experimentam suas diferentes situações, dentro do conjunto das relações sociais, com suas culturas e expectativas herdadas, e enquanto lidam com estas experiências de maneiras culturais.” E, como para chamar a nossa atenção - nós estudantes de sociedades vivas - para a forma pela qual os estudantes do passado podem aguçar nossa percepção, Thompson acrescenta alguns exemplos úteis:

A exibição ostentatória, as perucas empoadas e os trajes dos poderosos também devem ser vistos - como se pretendia que fossem vistos - de baixo para cima, na platéia do teatro da hegemonia e do controle de classes. Até mesmo a 'liberalidade' e a 'caridade' podem ser vistas como atos calculados de apaziguamento de classes em tempos de escassez e extorsões calculadas (sob ameaça de motim) pela massa: o que é (vindo de cima) um 'ato de doação' é (vindo de baixo) um 'ato de ganho'. Uma categoria tão simples como o 'roubo' pode se transformar, sob certas circunstâncias, em evidência de esforços prolongados dos aldeões na defesa de velhos hábitos de direito comum, ou de trabalhadores na defesa de gratificações costumeiras.

O porquê de um historiador da Inglaterra do século XVIII ter tanta coisa útil a dizer aos antropólogos decorre, a meu ver, de diversos fatos da vida que têm pouco ou quase nada a ver com política. Thompson não aceita o conceito de uma cultura inteiramente coerente; na verdade, ele vê sua realidade em uma natureza um tanto difusa e modificável. Ele compreende o caráter fluido, de autoconstrução da identidade de classe e da consciência de classe, e reconhece que classe e cultura são similarmente produtos históricos dinâmicos. Mas, além de tudo isso, penso que ele se dirige a nós, antropólogos, porque precisamos, em algum momento, renunciar à ilusão de que as sociedades que estudamos não pertencem às esferas de poder e de influência mundial, peculiarmente 
protegidas das forças econômicas, sociais e políticas com as quais nós mesmos estamos bastante familiarizados. As sociedades que estudamos não se situam fora destas esferas - nem assim estiveram por longos séculos.

O fato de admitir esses princípios não nos torna instantaneamente sociólogos, como sapos que viram príncipes; ainda existe muita antropologia "real" a ser feita. E mais, podemos continuar a postular um mundo pleno de culturas independentes e coerentes, para sejam lá quais forem as propostas teóricas ou estéticas que imaginemos. Cultura é, em última análise e finalmente, comportamento mediado através de símbolos, e podemos fazer todo tipo de elucubração com, e sobre, esta questão. Mas chegou, sem dúvida, o momento de liberar nossa obsessão com um "primitivismo" semi-imaginado, ligado de algum modo a um igualmente dúbio "isolamento", o que resulta em uma visão de cultura perfeitamente coerente, monolítica, consistente internamente, e harmoniosa. Sabemos que o assunto não é simples; existem casos, na verdade, em que a "cultura" parece ser exatamente isso. Mas nós, antropólogos, temos de lidar com o mundo como ele é, como ele se tornou. Para tanto, creio que temos de renunciar à antiga visão de cultura, lembrar que é a nossa identidade comum de criaturas que utilizam símbolos que faz o mundo único - e começar tudo de novo.

Nota do Autor: Esta é a melhor ocasião para agradecer a Kai Erikson e Hans Medick por criticarem tão bem este ensaio, e para pedir desculpas por não ter conseguido transformá-lo em algo que agradasse a ambos. 